\title{
Open Co-creation Coming of Age: The Case of an Open Services Program Research-in-progress
}

\author{
Lieselot Danneels \\ KU Leuven \\ Vlerick Business School \\ lieselot.danneels@vlerick.com
}

\author{
Stijn Viaene \\ Vlerick Business School \\ KU Leuven \\ stijn.viaene@vlerick.com
}

\begin{abstract}
Co-creation has mostly been studied in the context of a single firm and in dyadic relationships, but much less in environments with multiple parties. In this article, we focus on open IT-based co-creation - a phenomenon at the intersection of co-creation, open innovation, and platform literature - and the organizational capabilities required to get the most out of it. We do this by investigating the revelatory case of a public employment service that opened internal IT services through co-creation with external organizations. Based on an embedded case study, we aim to explore the capabilities that help public services and their partners to be successful at open IT-based co-creation. In this research in progress, we focus primarily on the research design and already share some preliminary results.
\end{abstract}

\section{Introduction}

In 2013, VDAB (the public employment service of the Flemish region in Belgium) launched its open services program. VDAB opened internal IT services such that they could be used by external organizations in their own IT systems. This fits with VDAB's aim to fulfill a conducting function in the labor market, and to stimulate public, private and non-profit labor market actors to cooperate and innovate. The open services were developed in collaboration with external organizations (private recruitment and selection agencies, interim agencies, employers, start-ups, and other European public employment services) who assisted in co-creating these open IT artifacts. While the external organizations were part of the broader labor market ecosystem, they were normally no direct business partners, customers or suppliers of VDAB.

The case of VDAB's open services program and the more general phenomenon of open IT-based cocreation are linked to three important trends. First, in a more and more digitized and networked world, the private and public sector are faced with challenges and opportunities that cannot be addressed by single organizations, or sometimes even single industries [11]. Therefore, organizations no longer limit their focus to what they are capable of on their own, but more and more look at what they can do together with others, including partner organizations, customers and start-ups [29]. In other words, we increasingly see organizations co-creating value in a cooperative manner [17]. Second, while in the past co-creation took place in one-on-one alliances with customers or suppliers, we now see open partner networks [11] innovating based on inflows and outflows of information in the network. Third, digital technologies create new possibilities for collaboration. Digital platforms enable new forms of co-creation [17], such as organizations opening their assets for others to innovate upon. Examples include open government data platforms, such as the London DataStore, where the city of London aims to openly exploit its data by co-creating an open data platform together with NHS, power companies and utilities [3].

Despite the increasing importance of co-creation, open innovation, and technological platforms, little is known about the capabilities that make organizations successful at open IT-based co-creation.

A review of the IT-based co-creation literature revealed that very few studies focus on co-creation with multiple partners in an open partner network [19]. While most research on co-creation takes a single organization perspective, and only some research focuses on dyadic relationships, very little research is performed on more open forms of collaboration [19].

Another noticeable gap is that technology-related considerations often remain absent in studies on cocreation [24][17], while digital technologies can be an important enabler for co-creation.

In the public sector research community, on the one hand, a technology perspective is lacking in much of the research on co-creation and co-production [31][21]. On the other hand, the ample research on open 
(government) data focuses mostly on how to technically open up government information for external re-use by stakeholders, while the co-creation aspect is missing [1][18].

Finally, while the co-creation case study research presents several cases showing mature forms of cocreation (e.g., ERP systems [24] and cloud ecosystems [16]) we are not aware of any case studies on organizations that are starting with a co-creation program by opening assets in a co-creative way.

Our research objective is to empirically develop an understanding of the co-creation of an open IT artifact with multiple organizations, in a government context. Therefore, this article aims at answering the research question: what does it take to co-create in an open partner network, based on digital technologies? This overarching research question is tackled by answering four underlying questions: (1) how does co-creation of an open IT artifact differ from traditional co-creation? (2) how does a public service start with open cocreation? (3) which capabilities does a public service use to co-create value with its partners? (4) which capabilities do partner organizations use? To answer the research questions, we investigate the revelatory case of VDAB, the public employment service of the Flemish region in Belgium, and its 5-year program with open services. We perform an embedded case study, looking at VDAB's open services program in general and at three different sub-cases of organizations co-creating and using a set of open services.

The rest of this research-in-progress article is organized as follows. Section 2 discusses important aspects identified by the three literature streams linked to open IT-based co-creation: IT-based co-creation, open innovation, and technological platforms. Section 3 describes the case context, and discusses the methodology we use in this study. Section 4 presents the preliminary results based on the case study data with respect to open IT-based co-creation. Section 5 concludes the article with a summary of the contributions of the research-in-progress, and a discussion of what we aim to achieve in the full paper.

\section{Key theoretical perspectives for studying open IT-based co-creation in government}

In our revelatory case study, we can discern several aspects: VDAB creates an open IT artifact by opening internal IT services to be used by other organizations in their own systems, and this artifact is created in collaboration with other organizations. In an effort to understand these aspects, we reviewed the IT-based cocreation literature, studies focusing on open innovation, the technological platform literature, and government literature. While the IT-based co-creation literature studies the ways to combine resources for cocreation through alliances or collaboration between different actors, research primarily focuses on dyadic relationships and not on open partner networks [19]. The open innovation literature and studies focusing on technological platforms both discuss the impact of openness. The open innovation literature, which focuses on internal and external sources for ideas and ways to market them, also points to the importance of moving from a company to an ecosystem logic. The literature on technological platforms suggests the important role of governance when opening internal assets. Public sector literature provides insight in what co-creation, open innovation, and technological platforms look like in a specific context. We discuss these factors in further detail below, and summarize them in Table 1.

Table 1. Key theoretical pers pectives for s tudying open IT-based co-creation in government

\begin{tabular}{|c|c|c|}
\hline $\begin{array}{l}\text { Case } \\
\text { elements }\end{array}$ & $\begin{array}{l}\text { Literature } \\
\text { s tream }\end{array}$ & Pers pectives \\
\hline $\begin{array}{l}\text { Co-creating } \\
\text { business } \\
\text { value with } \\
\text { other actors }\end{array}$ & $\begin{array}{l}\text { IT-based co- } \\
\text { creation }\end{array}$ & $\begin{array}{l}\text { - } \begin{array}{l}\text { Modes of co- } \\
\text { cre ation } \\
{[17][24][23][4][15]} \\
{[14]}\end{array} \\
\end{array}$ \\
\hline $\begin{array}{l}\text { Opening } \\
\text { assets for } \\
\text { innovation } \\
\text { by an open } \\
\text { network }\end{array}$ & $\begin{array}{l}\text { Open } \\
\text { innovation }\end{array}$ & 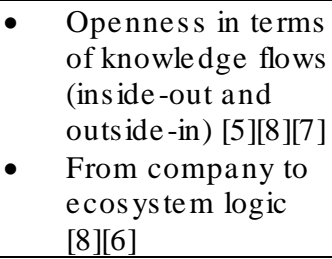 \\
\hline $\begin{array}{l}\text { Designing } \\
\text { an IT artifact } \\
\text { that can be } \\
\text { used by } \\
\text { other parties }\end{array}$ & $\begin{array}{l}\text { Technological } \\
\text { platforms }\end{array}$ & $\begin{array}{l}\text { - Openness in terms } \\
\text { of access and } \\
\text { control of the } \\
\text { platform }[26][32] \\
\text { Governance } \\
{[2][13][25]}\end{array}$ \\
\hline
\end{tabular}

\subsection{IT-based co-creation}

Co-creation has been defined by Sarker et al. [24] as "a symbiotic relationship between a firm and its primary stakeholders [17], wherein the stakeholders (i.e., the focal firm with its partners or clients) customize and co-produce products/services [22]". Cocreation has been studied by marketing and service management literature as well as information systems literature. In marketing, co-creation is often framed using the service-dominant logic [27][28], with a focus on organizations co-creating services with customers. This article focuses on IT-based co-creation of value, 
where IT serves as a tool, an output, or is instrumental in generating the co-creation of business value [17]. IT-based co-creation of value represents the idea that "(a) IT value is increasingly being created and realized through actions of multiple parties, (b) value emanates from robust collaborative relationships among firms, and (c) structures and incentives for partners to partake in and equitably share emergent value are necessary to sustain co-creation" [Koch 2010].

Two main themes are important in the (IT-based) co-creation literature [14]: generation of value and the distribution or appropriation of the value [4][15]. For the open services phenomenon, especially the generation of value is relevant: in a public employment services context, the main value created is getting people to work, so distribution or appropriation of value is less of an issue (at least for initial co-creation efforts).

IT-based generation of value focuses on bringing disparate collaborative resources together [24][23]. Sarker et al [24] describe the mechanisms underlying value co-creation as three different modes of cocreation: exchange, addition, and synergistic integration. In the exchange mode of co-creation, "two participants in an alliance develop value by each providing resources / competencies the other partner needs". In the addition mode, "one of the two parties builds on the contributions of the other in order to create value for both". In the synergistic integration mode, both sides "(1) have to work together with each other, in a mutually reinforcing manner, (2) surrender some of their own autonomy, (3) have trust in the other to do what is in the interest of both sides of the relationship, and (4) invest in the relationship rather than just look for gains in it" [22].

The IT-based co-creation literature provides us insights into the ways to combine resources for co-creation of business value with different actors, but a focus on open partner networks is missing [19]: only some research focuses on dyadic relationships, and very little research is performed on more open forms of collaboration. This is an important gap, since cocreation in open alliances differs from more closed forms of co-creation in its strategic scope and scale, governance mechanisms, member composition, and evolutionary dynamics [15].

\subsection{Open innovation}

To add the element of openness to the co-creation literature, we reviewed the open innovation literature. Open innovation is defined as "a distributed innovation process based on purposively managed knowledge flows across organizational boundaries, using pecuniary and non-pecuniary mechanisms in line with the organization's business model" [7] and contrasts to a closed innovation model, where "internal innovation activities lead to internally developed products and services that are then distributed by the firm" [5]. It places external ideas and external paths to market on the same level of importance as that reserved for internal ideas and paths to markets in the traditional closed innovation paradigm [8]. Chesbrough [5] defines two types of open innovation: outside-in and inside-out. The outside-in type focuses on the opening of a company's innovation process to many kinds of external inputs and contributions. The inside-out type allows unused and underutilized ideas to go outside the organization for others to use in their business and business models.

Open innovation implies a shift from a company to an ecosystem logic [6]. Not only can value be created through a community or network (opposed to in-house only), the value is no longer captured by a single company, but by the complete ecosystem. This contrasts with the closed innovation model, where opening towards the external environment was only done for serving internal purposes of the company [8].

\subsection{Technological platforms}

The technological platform literature adds to the previous literature streams a focus on the platform artifact which enables a network of organizations to build on another organization's assets.

Gawer [12] defines technological platforms as "evolving organizations or meta-organizations that (1) federate and coordinate constitutive agents who can innovate and compete; (2) create value by generating and harnessing economies of scope in supply or/and in demand; and (3) entail a modular technological architecture composed of a core and a periphery".

Important debates in the platform literature centre around two interesting themes: openness [2] and governance [26][32]. Although the themes are to some extent interdependent (e.g., the degree of openness impacts governance), we distinguish the two themes by explaining their components.

Regarding openness, there are two distinct approaches to opening a technology platform: granting access to the platform, and opening the control over the platform [2]. The platform provider can "grant access to the platform and thereby open up markets for complementary components around the platform" [2]. The openness of the platform is therefore partly determined by the openness of the platform architecture [26], a conceptual blueprint describing "a relatively stable platform and a complementary set of modules that are encouraged to vary, and the design rules binding on both". The platform provider can also 
give up control over the platform itself [2][13][25]. In other words, the platform can be proprietary to a single organization, or shared by multiple owners [26]. Also the decision rights can vary in openness in dividing decision-making authority between the platform provider and complementors [26]. Deciding on the openness of the platform is not a trivial task, and requires the consideration of significant trade-offs: more openness stimulates the adoption of the platform but lowers its appropriability, and stimulates diversity but reduces the platform provider's control [2].

Platform governance is crucial to manage such trade-offs and other tensions [26][32]. Wareham et al. [32] distinguish three salient tensions linked to the stability-evolvability trade-off which require appropriate governance: standard-variety, controlautonomy, and collective-individual. In the outputs, or complements built on the platform components, standardization has to be balanced relative to the creation of specialized complements and constant experimentation. Towards the actors linked to the platform, control on the quality of the process, product, and excess supply has to be balanced with mechanisms leveraging the autonomy for innovation. In the identifications of the platform actors, each individual actor should be able to work towards its own benefit, but this has to be balanced with a focus on the collective benefits for the entire network. Tiwana et al. [26] summarize the control mechanisms to encourage desirable behaviour by complementors (and vice versa) as formal (output and behaviour) control, informal clan control, and input control.

The technological platform literature adds to research on co-creation and open innovation a focus on the platform artifact, and important considerations for its design (openness and governance). On its own, however, the platform literature would not be able to explain the open services phenomenon as a collaboration aspect for building the platform (rather than only its components) is missing.

\subsection{Public sector context}

In the public sector literature and in studies on digital government, we did not find any studies capturing all case aspects described in the IT-based cocreation, open innovation, and technological platform literature. We did find studies focusing on one or two of the literature streams. Although public sector literature does not provide us with theoretical frameworks to study the phenomenon at hand, it does provide us with a focus on the specific context that might have an impact on the case.

In a public sector context, co-creation is often used interchangeably with co-production [31], with both terms focusing mainly on the involvement of citizens as end-users in the design, management, delivery and/or creation of public services [21] rather than on co-creation with (multiple) organizations. In the research on co-creation and co-production, a technology perspective is lacking [31][21].

Open innovation studies in government often do not take IT into account, such as Feller et al.'s [10] research on a network of municipalities in Sweden collaborating with each other and with external parties to accelerate innovation. One exception is the case study of challenge.gov, which crowdsources solutions to tackle complex public management problems [20]. In this study, Mergel and Desouza argue that open innovation approaches from the private sector cannot be readily transferred to the public sector, because a political mandate is required for innovation and special rules and regulations, such as contracting rules, govern the interaction with the public sector [20].

One of the most eminent examples of technological platforms in government are open data platforms. The abundant research on open data focuses mostly on how to technically open government information for re-use by external stakeholders, while the co-creation aspect is missing [1][18].

\section{Case and methodology}

\subsection{Case context: VDAB's open services program}

Founded in 1989, VDAB (Vlaamse Dienst voor Arbeidsbemiddeling en Beroepsopleiding) is the public employment service (PES) for the Flemish region in Belgium (Flanders). It offers employment services, training, and career guidance to society at large.

In 2013, VDAB started the open services program. IT services that were used internally were opened, in small pieces, such that other labor market actors could embed them in their own IT systems. The development and further improvement of the open services takes places in co-creation with external organizations, such as private recruitment and selection agencies, interim agencies, employers, start-ups, and other European public employment services. While these external organizations are part of the larger labor market ecosystem, they are no direct customers or suppliers of VDAB.

The first project that was part of the open services program consisted of the development of the Comeet service together with Randstad, Tempo-Team and Konvert, three recruitment and selection agencies. In 2014, the Comeet service was also opened to other organizations. Today, VDAB offers 8 different open 
services, summarized in Table 2, which are still further co-developed with over 20 partner organizations using the open services.

To understand the open services, it is important to note that VDAB matches job candidates to vacancies based on competences rather than on job titles, to also include job seekers with a certain affinity to the job, and for better reorientation towards shortage occupations. VDAB is one of the forerunners in Europe in using and promoting competence-based matching.

Table 2. VDAB's open services

\begin{tabular}{|ll|}
\hline CV & Description \\
\hline Vacancy & $\begin{array}{l}\text { Export CVs, if citizens agree to have } \\
\text { their data transferred to partner } \\
\text { databases }\end{array}$ \\
\hline Comeet & $\begin{array}{l}\text { Export vacancies } \\
\text { templates }\end{array}$ \\
\hline $\begin{array}{l}\text { Online } \\
\text { As is tant }\end{array}$ & $\begin{array}{l}\text { Automatic comments on contradictory } \\
\text { or incomplete items in a vacancy }\end{array}$ \\
\hline Study Tree & Lists all recognized types of education \\
\hline Wordcloud & $\begin{array}{l}\text { Suggests words that are commonly } \\
\text { associated with a vacancy the user is } \\
\text { introducing }\end{array}$ \\
\hline Matching & $\begin{array}{l}\text { Gives a list of matching candidates for } \\
\text { a certain vacancy }\end{array}$ \\
\hline $\begin{array}{l}\text { Matching as } \\
\text { a service }\end{array}$ & $\begin{array}{l}\text { Same as above, implemented in the } \\
\text { partner organization's own systems }\end{array}$ \\
\hline
\end{tabular}

The open services program fits with VDAB's strategy and the strategy of the network of European public employment services, which both acknowledge that public employment services will have to organize strong alliances and networks of public, private and non-profit organizations. For the EU 2020 strategy, it is a critical success factor that the public employment services acquire a mandate to fulfil conducting functions which include, amongst others, stimulating labor market actors to cooperate and innovate, collaborating closely with public or private partners and aligning labor market actors with labor market policy. VDAB's strategy, VLAM 2020, puts forward three strategic decisions: networking with partners as an orchestrator, providing omni-channel services, and being a strong brand for work. The importance of networks and collaboration is also recognized by VDAB's CEO:

"Today $V D A B$ is surrounded by a number of innovative organizations focused on the labor market, matching and (professional) education. From our encounters with these new actors we see that networking and collaborating is the only value-adding strategy for them and for us. Therefore VDAB's orientation as network orchestrator requires further professionalization and expansion of the conducting functions, but also the realization of an 'open services' platform." [30]

\subsection{Methodology}

We adopt a revelatory embedded case study approach [33]. Since there is a lack of in-depth field studies on the rather new phenomenon of open ITbased co-creation, we chose to study a case that could potentially be a unique and exemplary source of insight on this phenomenon in depth. VDAB's open services program focuses on the phenomenon of interest, open IT-based co-creation, has been going on for a long time and could be investigated in depth. VDAB's case can be seen as exemplary since the public service is one of the forerunners in Europe when it comes to digital innovation of public services [9]. Throughout VDAB's open services program, 8 different services have been co-created with more than 20 partners. We chose to balance a narrow, detailed focus on specific services with a broad, more general focus on the program as a whole through an embedded case study approach. Thus, we complement the focus on the VDAB's open services program in general with embedded cases, focusing on a service (or set of services) used by one (ore more) partner organizations.

For selecting theoretically useful cases, two criteria were identified: the modes of co-creation in the open services, and the familiarity between VDAB and the partner organizations.

Table 3. Co-creation modes (based on [24])

\begin{tabular}{|lll|}
\hline Mode & Criteria & $\begin{array}{l}\text { Open } \\
\text { services }\end{array}$ \\
& $\begin{array}{l}\text { Each partner provides } \\
\text { resources or } \\
\text { competencies the } \\
\text { other partner needs }\end{array}$ & $\begin{array}{l}\text { CV, } \\
\text { Vacancy, } \\
\text { Comeet, } \\
\text { Online } \\
\text { Ass istant, } \\
\text { Study } \\
\text { Tree, }\end{array}$ \\
& $\begin{array}{l}\text { Wordcloud, } \\
\text { Matching }\end{array}$ \\
\hline Addition & $\begin{array}{l}\text { Considerable } \\
\text { alignment of } \\
\text { resources is required }\end{array}$ & $\begin{array}{l}\text { Matching } \\
\text { as } \\
\text { service }\end{array}$ \\
\hline $\begin{array}{l}\text { Synergis tic } \\
\text { integration }\end{array}$ & $\begin{array}{l}\text { Learning-based value } \\
\text { is important }\end{array}$ & None \\
& $\begin{array}{l}\text { Rent-earning capacity } \\
\text { is sustainable over } \\
\text { time and transferable } \\
\text { outside the alliance }\end{array}$ & \\
\hline
\end{tabular}

The first criterium resulted from the IT-based cocreation literature, where Sarker et al. [24] make a distinction between three different modes of cocreation with different degrees of resource alignment, 
see section 2.1. We expected the degree of resource alignment to be related to the capabilities needed for open IT-based co-creation. Sarker et al. [24] see the three modes of co-creation as a continuum and define the necessary criteria for advancing to a mode with a higher degree of resource alignment, see Table 3. Each co-creation mode is then characterized by the criteria of lower level modes as well, but does not show higher level criteria yet. We used these criteria to identify the mode of co-creation for each open service. Seven of VDAB's open services were classified as exchange and one open service as addition, see Table 3.

The second criterium for selecting cases is more grounded and resulted from the case, our previous relationship with $\mathrm{VDAB}$, and an analysis of the set of partners that are using VDAB's open services. We expected that the degree to which VDAB already collaborated in the past with the partner organizations might have an effect on the capabilities required for cocreation. We identified, together with VDAB's open services program manager, whether VDAB had a history of collaboration with the partner organizations during the normal course of business and whether VDAB had co-created with the partner organizations before the start of the open services program. We verified the outcomes with VDAB's CIO and CEO, and for the selected cases we also verified the result with the partner organizations.

Table 4. Cas e selection

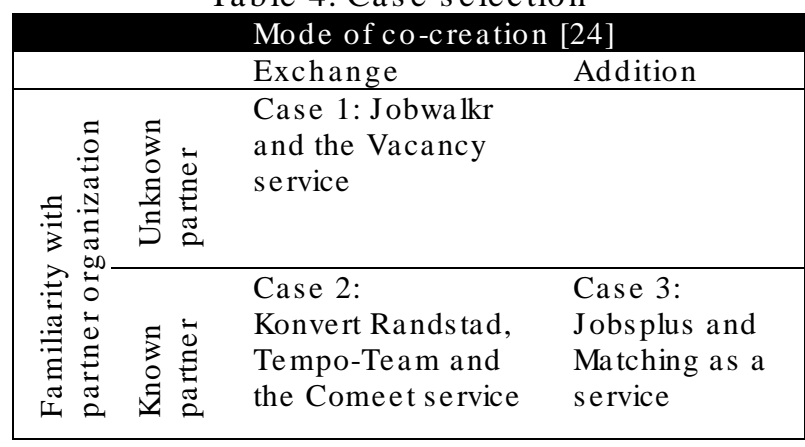

Juxtaposing the two selection variables resulted in the selection of theoretically useful cases. In Table 4 we present our selection of embedded cases, which consist of a partner organization and the set of open services co-created with that organization. In the addition mode, VDAB currently only has one partner (Jobsplus) using matching as a service.

Our prolonged relationship with VDAB allowed for an intensive data collection on open IT-based cocreation through semi-structured interviews and other documentary evidence. We had access to internal VDAB documentation on the open services and on the partner organizations using the open services, and to the website providing information to the partner organizations. All of this documentation contributed to our broader understanding of VDAB's open service environment. The authors continually followed VDAB's digital innovation projects, of which the open services were part, through monthly steering committee meetings and workshops from January 2014 up to now. For investigating the capabilities required for open IT-based co-creation, 7 interviews were conducted between February and June 2017, focusing on the capabilities that were important during the open services program from the point of view of VDAB and its partner organizations. The semi-structured interviews were carried out with the responsibles for the open services program, both at VDAB and its partner organizations, see Table 5. During the interviews, we explained the study's objectives and research questions, and we focused on the most important capabilities for the success of the open services program, as identified by the interviewee. Each interview lasted between 40 minutes and 2 hours, and notes were taken during the interviews. All interviews were recorded and transcribed.

As this is a research-in-progress contribution, the data analysis phase has not been finalized yet. The interview transcripts have already been coded based on the criteria for case selection (i.e., modes of cocreation, and familiarity with the partner organization). In a next step, we will aim to identify the most important capabilities for VDAB and for the partner organizations that were mentioned in the interviews, organize these capabilities under the three major theoretical categories (i.e., IT-based co-creation, open innovation, and technological platforms), and distinguish between the different embedded cases.

\section{Results}

In this section we share some first results from the interviews, describing the case of VDAB's open service program as a whole and zooming in on the selected embedded cases and how they illustrate two different modes of open IT-based co-creation. Further analysis and coding of the interview transcripts is necessary to also present the capabilities that were important for VDAB and its partner organization. In a next version of this article, we aim to discuss these capabilities in the light of the literature on IT-based cocreation, open innovation, and technological platforms. 
Table 5. Organizations and profiles of the intervie wees

\begin{tabular}{|c|c|c|}
\hline Organization & Brief des cription & Interviewee position / role \\
\hline \multirow[t]{3}{*}{ VDAB } & \multirow{3}{*}{$\begin{array}{l}\text { Public employment service of the Flemish re gion in Be lgium, } \\
\text { offering e mployment services, training, and career guidance } \\
\text { to s ociety at large. }\end{array}$} & $\mathrm{CEO}$ \\
\hline & & $\mathrm{CIO}$ \\
\hline & & Open services program manager \\
\hline Konvert & Family firm focusing on recruitment and selection & $\mathrm{CIO} / \mathrm{CTO}$ \\
\hline Randstad & $\begin{array}{l}\text { HR service provider, focusing amongst others on temporary } \\
\text { jobs, and recruitment and selection. }\end{array}$ & \multirow[t]{2}{*}{ Business Performance Manager } \\
\hline Tempo-Team & $\begin{array}{l}\text { HR service provider, part of Randstad Holding, focus ing } \\
\text { a mongst others on temporary jobs, recruitment and selection }\end{array}$ & \\
\hline Jobwalkr & $\begin{array}{l}\text { Startup that de veloped an app to inform users when relevant } \\
\text { job opportunities are a vailable in the ir neighborhood. }\end{array}$ & 3 s tart-up owners \\
\hline Jobsplus & Public employment service of Malta & $\begin{array}{l}\text { IT Department Manager, and } \\
\text { Labor Market Information } \\
\text { Department Manager }\end{array}$ \\
\hline
\end{tabular}

\subsection{Becoming co-creative}

For VDAB, the process of becoming a co-creative organization already started almost a decade ago. Two separate systems for introducing vacancies, one for internal consultants and one for external clients, were merged into one vacancy portal where VDAB employees and interim agencies as well as employers could introduce and follow up vacancies. In a next phase, as requested by several interim agencies, separate interfaces were developed for each external party such that they could introduce vacancies to the VDAB portal directly from their own systems. However, it did not take long before VDAB decided together with Federgon, the federation of labor market companies, to use one standard HR-XML interface for all parties. The collaboration with Federgon proved to be very important in convincing the labor market companies to make the switch:

"The most important question was whether the organizations were going to accept a standard forced on them by VDAB. From the point of view of VDAB it was much easier to work with one standard interface. But will they be willing to adapt the hundreds of systems out there? [...] As soon as we were able to convince some of the biggest players, the whole sector understood that it could lead to productivity gains for everyone. And Federgon really helped us in convincing them." - CIO VDAB

It was only a logical next step to evolve towards multiple open services which allowed partner organizations to also export vacancies and CVs from VDAB's databases (the vacancy and CV service in Table 1) or to improve the quality of the vacancies (Online Assistant service in Table 1). Figure 1 gives an overview of the situation in June 2017, listing for each open service how many organizations showed interest in it, how many had a first discussion about it with the open services team, how many are implementing the open service to be used in their own systems, and how many are actually using the service.

The motivation for VDAB to start with open services was clear from the start, and is also embedded in VDAB's strategy and the European PES strategy:

"We are part of a network society, both in the labor market and in the broader economy. It's illusory to think that you can have an impact on the policy domain as a closed organization. On top of this, all government organizations are facing budgetary constraints. It is necessary to look for new types of collaboration with the private sector." - CEO VDAB

\subsection{Open IT-based co-creation exchange}

We classified the embedded cases of Konvert, Randstad, and Tempo-Team (and the Comeet service), and Jobwalkr (and the Vacancy service) in the exchange mode of co-creation, since each partner provides resources or competencies the other partner needs.

For the partner organizations in the selected embedded cases, the motivation to start using and cocreating VDAB's open services was quite diverse. Konvert, Randstad and Tempo-Team were part of the first open services pilot, in which they co-created the Comeet service. Randstad and Tempo-Team are now mainly using the Comeet service to experiment with the intake of external services and to learn how this can enrich their own data. Konvert was implementing a new CRM system, requiring new competence templates, and now uses three other open services as well: the vacancy service, CV service, and Online Assistant. The start-up Jobwalkr uses the vacancy service for its app showing all jobs in your area on a map. 


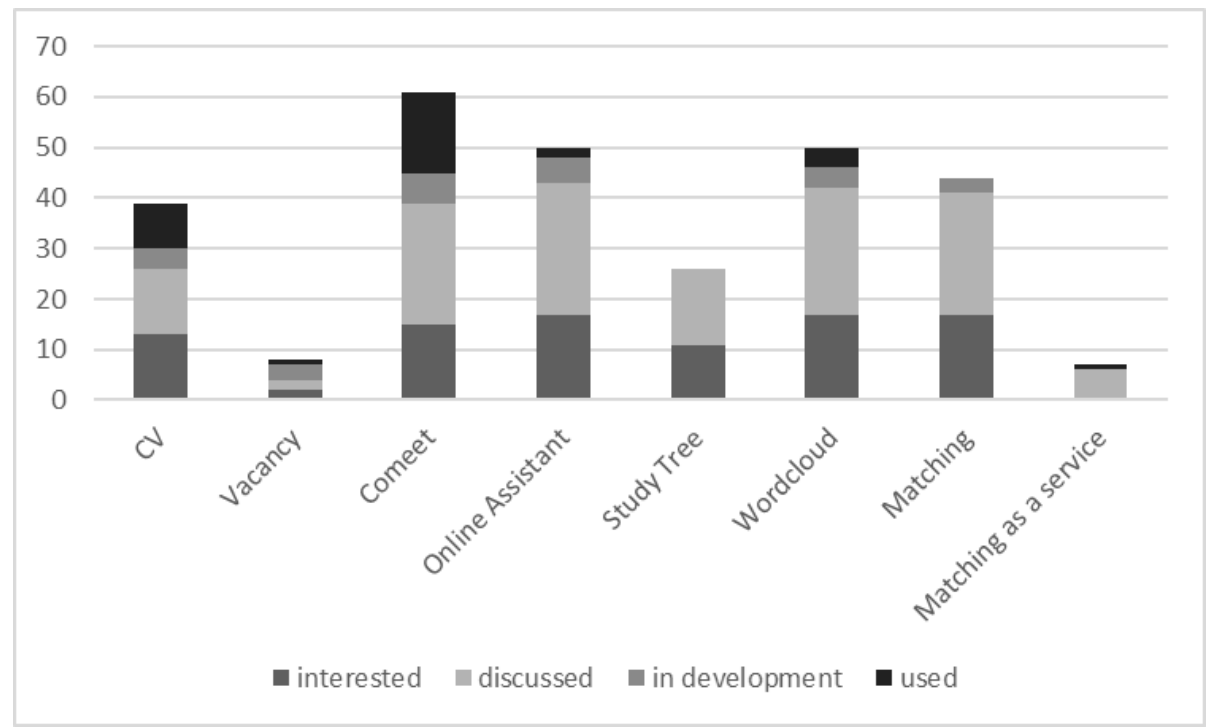

Figure 1. Us e of the open services

From the point of view of VDAB, insights were needed on how to best present and develop the open services for external use:

"[We had to] discuss with the individual companies, convince them to use our services, try to capture their questions, and which services are relevant to them. This is something a government organization traditionally doesn't do, taking up this seller role, convincing companies to use their services." - CIO VDAB

The partner organizations recognized that the cocreation process added value to the open services:

"This is one of the most important things for me: they [VDAB] made the effort to listen to their customers and this has enriched the open services. I still have to sell it internally, but it is clearly a product that has added value... I mean, look at the amount of customers they have." - Randstad

The main difference with a more closed model of co-creation, in which VDAB would work in one-onone alliances rather than in an open partner network, is that the services had to be designed with several parties in mind:

"We want to offer the open services to a broad audience. Many organizations merge, or switch focus from interim services towards broader HR services. We cannot focus on one part of the labor market only, but have to make sure that we have a maximum impact on the entire labor market. This means trying to recognize commonalities among actors and developing services based on these commonalities." - CEO VDAB

The partner organizations appreciated this open approach:
"Every party had the feeling that they were welcome and they [VDAB] give equal attention to every question. Even smaller players with a question get an equal amount of attention. It [the open service] was not made for us. It is designed together with us, but not exclusively for us. [...] It was nice to start from smaller groups to eventually co-create a product that could be used in the whole sector." - Randstad

Compared to the addition mode of co-creation, however, implementation efforts in the exchange mode were limited for the partner organizations. Randstad and Tempo-Team added a new step in the process to publish vacancies internally, and the recruitment and selection agency's personnel was already familiar with using the service on VDAB's website. For Konvert, total development time took longer, but was part of the implementation of a new CRM system. For the partner organizations, it was still important to think about possible issues beforehand:

"How can we, together with VDAB, make sure that new professions [and their competence templates] will immediately be available in the system? What if a profession is deactivated in VDAB's system, how will this be translated into our systems? This was not a real concern, but definitely something we had to think about during the analysis phase." - Konvert

For VDAB, alignment of resources was also more limited compared to the addition mode, although it was important to already think upfront of the impact of external use of the open services on their own systems:

"Technically and operationally it's important for the open services to make sure that they are stable 24/7. You need to perform monitoring, performance tests, daily availability tests, have a fallback component... By working with an external system you can also bring 
down your whole system, all applications. So you need to take measures to prevent that, such as throttling." $\mathrm{CIO}$ VDAB

\subsection{Open IT-based co-creation addition}

Jobsplus, the Public Employment Service of Malta, did not have an in-house competence-based matching system and wanted to rely on a system used and tested by another PES rather than to reinvent the wheel. What convinced Malta to use VDAB's open services was the fact that VDAB could prove that it was already successfully providing open services to the private sector.

We classified the case of Jobsplus using matching as a service in the addition mode of co-creation, since considerable alignment of resources was necessary. The total implementation project took 18 months, but this also included building a new website, new services and applications. The contract building was difficult, as the project involved several contractors, and none of the public employment services were familiar with service delivery and contracting with another public employment service. Using the open services had implications on internal business processes as well, and even on the relations with partners:

"The employment service division had to go through a culture change: from very basic skills to another layer of training from our side. We even need to train employers to use these competences for proper matching as well, rather than just mentioning job names." - Jobsplus

Compared to the exchange mode, the IT-based cocreation addition mode was less open. The open service was heavily customized according to Jobsplus' matching process, and for future re-use, the customizing will be different.

\section{Conclusion}

In this research-in-progress, we already report the first observations from an embedded case study at VDAB, the public employment service of the Flemish region in Belgium, and its 4-year program with open services. Through the literature on IT-based cocreation, technological platforms and open innovation we identified key theoretical perspectives for studying open IT-based co-creation in government. The case narrative showed how a public service starts with open IT-based co-creation and what different modes of resource combination look like in an open IT-based cocreation phenomenon in a government context. We expect that this research-in-progress will contribute to a more dynamic perspective on the subject, by zooming in on the move towards becoming cocreative.

In the full paper we aim to uncover the most important capabilities for a public service to co-create value with its partners, and the capabilities for the partner organizations, in the light of the key theoretical perspectives identified in the literature section. As this research is an early stage single-case study, there will be a need for more research to validate our provisional findings regarding the capabilities for open IT-based co-creation.

\section{Acknowledgments}

This research was supported by the VDAB research chair on digital business innovation of public services at KU Leuven.

\section{References}

[1] J. Attard, F. Orlandi, S. Scerri, and S. Auer, "A systematic review of open government data initiatives", Government Information Quarterly, 32(4), 2015, 399-418.

[2] K. Boudreau, "Open platform strategies and innovation: Granting access vs. devolving control", Management Science, 56(10), 2010, 1849-1872.

[3] J. Card, "Open data is at the centre of London's transition into a smart city", The Guardian, 3 August 2015, URL: https://www.theguardian.com/media-network/2015/aug/03/ open-data-london-smart-city-privacy (Accessed on 14 June 2017).

[4] M. Ceccagnoli, C. Forman, P. Huang, and D.J. Wu, "Cocreation of value in a platform ecosystem: The case of enterprise software”, MIS Quarterly, 36(1), 2012, 263-290.

[5] H. Chesbrough, "Open innovation: Where we've been and where we're going", Research-Technology Management, 55(4), 2012, 20-27.

[6] H. Chesbrough, and M. Appleyard. "Open innovation and strategy", California management review, 50(1), 2007, 57-76.

[7] H. Chesbrough, and M. Bogers, "Explicating open innovation: Clarifying an emerging paradigm for understanding innovation", New Frontiers in Open Innovation, 2014, 3-28.

[8] H. Chesbrough, W. Vanhaverbeke, and J. West, Open innovation: researching a new paradigm, Oxford University Press, Oxford, UK, 2006.

[9] L. Danneels, S., and S. Viaene, "Simple rules strategy to transform government: an ADR approach", Government Infortmation Quarterly, 32(4), 2015, 516-525. 
[10] J. Feller, P. Finnegan, and O. Nilsson, "Open innovation and public administration: transformational typologies and business model impacts", European Journal of Information Systems, 20, 2011, 358-374.

[11] N. Furr, K. O'Keeffe, and J.H. Dyer, "Managing multiparty innovation: How big companies are joining forces to seize opportunities at their intersections", Harvard Business Review, 94(11), 2016, 76-83.

[12] Gawer, A. (2014). Bridging differing perspectives on technological platforms: Toward an integrative framework. Research Policy, 43(7), 1239-1249.

[13] A. Ghazawneh, and O. Henfridsson. "Balancing platform control and external contribution in third-party development: the boundary resources model", Information Systems Journal, 23(2), 2013, 173-192.

[14] V. Grover, and R. Kohli, "Cocreating IT value: New capabilities and metrics for multifirm environments", MIS Quarterly, 36(1), 2012, pp. 225-232.

[15] K. Han, W. Oh, K.S. Im, R.M. Chang, H. Oh, and A. Pinsonneault, "Value cocreation and wealth spillover in open innovation alliances", MIS Quarterly, 36(1), 2012, pp. 291325 .

[16] J. Huntgeburth, M. Blaschke, and S. Hauff, "Exploring value co-creation in cloud ecosystems: a revelatory case study", European Conference on Information Systems, 2015, paper 82 .

[17] R. Kohli, and V. Grover, "Business value of IT: An essay on expanding research directions to keep up with the times", Journal of the AIS, 9(1), 2008, pp. 23.

[18] G. Maccani, B. Donnellan, and M. Helfert, "Exploring the Factors that Influence the Diffusion of Open Data for New Service Development: an Interpretive Case Study", In ECIS 2015: Proceedings of 23rd European Conference on Information Systems, 2015, Münster, Germany.

[19] M. Mandrella, S. Zander, and L.M. Kolbe, "IT-based value co-creation: A literature review and directions for future research", Hawaii International Conference on System Sciences, 2016, p. 287-296.

[20] I. Mergel, and K.C. Desouza, "Implementing open innovation in the public sector: The case of Challenge. gov", Public administration review, 73(6), 2013, 882-890.

[21] S.P. Osborne, Z. Radnor, and K. Strokosch, "Coproduction and the co-creation of value in public services: A suitable case for treatment?", Public Management Review, 18(5), 2016, 639-653.

[22] A.F. Payne, K. Strobacka and P. Frow, "Managing the co-creation of value", Journal of the Academy of Marketing Science, 36(1), 2008, 83-96.

[23] A. Rai, P.A. Pavlou, G. Im, and S. Du, S, "Interfirm IT capability profiles and communications for cocreating relational value: evidence from the logistics industry", MIS quarterly, 36(1), 2012, 233-262.

[24] S. Sarker, S. Sarker, A. Sahaym, and N. BjornAndersen, "Exploring value cocreation in relationships between an ERP vendor and its partners: A revelatory case study", MIS Quarterly, 36(1), 2012, pp. 317-338.

[25] A. Tiwana, "Evolutionary competition in platform ecosystems", Information Systems Research, 26(2), 2015, 266-281.

[26] A. Tiwana, B. Konsynski,, and A.A. Bush, "Research commentary-Platform evolution: Coevolution of platform architecture, governance, and environmental dynamics", Information Systems Research, 21(4), 2010, 675-687.

[27] S.L. Vargo, and R.F. Lusch, "Evolving to a new dominant logic for marketing, Journal of Marketing, 68(1), 2004, 1-17.

[28] S.L. Vargo, and R.F. Lusch, "Service-dominant logic: continuing the evolution", Journal of the Academy of Marketing Science, 36(1), 2008, 1-10.

[29] S. Viaene, and L. Danneels, "Driving digital: Welcome to the ExConomy!", The Journal of Financial Perspectives, 3(3), 2015, 182-187.

[30] S. Viaene, and S. Broeckx, "How IT enables business model innovation at the VDAB", Journal of Information Technology Teaching Cases, e-pub, 2013, 1-10.

[31] W.H. Voorberg, V.J.J.M. Bekkers, and L.G. Tummers, "A systematic review of co-creation and co-production: Embarking on the social innovation journey", Public Management Review, 17(9), 2015, 1333-1357.

[32] J. Wareham, P.B. Fox, and J.L. Cano Giner, "Technology ecosystem governance", Organization Science, 25(4), 2014, 1195-1215.

[33] R. Yin, Case study research: Design and methods, Sage Publications, 2014. 